\title{
Ensino e pesquisa: atividades conflituosas
}

CDD. 20.ed. 001

796.017

http://dx.doi.org/10.1590/1807-55092015000100159
Valdir BARBANTI*

*Escola de Educação Física e Esporte, Universidade de São Paulo.

\section{Resumo}

0 objetivo deste ensaio foi analisar o relacionamento entre a efetividade do ensino e a produtividade na pesquisa. Vários estudos mostram não haver relacionamento entre o ensino e a pesquisa. Baseado nessa revisão conclui-se que a crença comum que o ensino e a pesquisa são indissociáveis é um mito duradouro, não mais justificável.

Palavras-chave: Professores universitários; Ensino; Pesquisa; Extensão.

\section{Introdução}

Cristovam Buarque, ex-reitor da Universidade de Brasília, um dos mais importantes educadores brasileiros, dizia que a sociedade e suas instituiçóes têm o direito de empregar palavras de ordem e mesmo de aprisionar-se nelas sem um aprofundamento maior de seus significados e consequências, mas a universidade não. Por ser uma instituição de reflexão, náo pode se dar ao luxo de interpretar o mundo por chavốes, slogans e palavras de ordem sem uma análise cuidadosa de seus significados. Mas não é isso o que ocorre, lamentavelmente.

Às vezes a universidade consegue até mesmo ficar prisioneira de suas palavras, como aconteceu com a expressão "indissociabilidade do ensino, pesquisa e extensão" sem definir corretamente os conceitos. A frase foi incluída no Estatuto da Universidade de São Paulo de 1988 (Artigo 2º e na Constituiçáo Federal de 1988, no artigo 207 onde diz que as universidades deveriam gozar de autonomia técnico-administrativa e de gestão financeira e patrimonial, obedecendo ao princípio da indissociabilidade entre ensino, pesquisa e extensão. O resultado, porém, foi uma frase confusa que tenta impingir atividades indissolúveis, a cada universidade e a cada professor universitário. A consequência não foi outra: a indissociabilidade foi dissolvida pela realidade. Muitos dos que a defendem não a praticam.

A ideia inicial era correta: comprometer todo o ensino superior com a pesquisa, retirando-o da simples prática do exercício repetitivo, e, ao mesmo tempo, forçar uma aproximação do ensino e da pesquisa com a realidade, através da prática da extensão. O conceito da indissociabilidade de ensino, pesquisa e extensão pode até ser um ideal, mas ela é impossível do ponto de vista teórico e prático. O ensino, a pesquisa e a extensão como uma prática conjunta diz respeito ao conjunto da universidade brasileira, e não a cada professor ou a cada instituição em particular. Cada professor deveria ser livre para buscar suas vocações, inclusive dedicando-se mais ao ensino, ou à pesquisa ou à extensão. Muitos dos debates sobre a natureza do trabalho dos docentes são, em minha opiniấo, baseados em mitos e suposiçóes.

Estas suposiçóes contém uma variedade de crenças que ajudam a perpetuar a cultura existente, ao mesmo tempo em que estabelecem normas de comportamentos aos participantes dessa cultura. Dentro do conjunto de crenças existentes no meio acadêmico, especialmente entre os administradores e docentes, sobre a natureza do trabalho docente e a produtividade estáo: 1. o ensino, a pesquisa e os serviços de extensão são atividades comuns no trabalho de cada docente universitário; 2. o ensino e a pesquisa são atividades que se reforçam mutuamente e como consequência; 3 . o corpo docente pode simultaneamente ser produtivo no ensino e na pesquisa. Este discurso é utilizado é utilizado na contratação de novos docentes e (principalmente) na carreira docente. É na carreira docente que se professa diferentes valores sobre os vários aspectos do trabalho docente. Aqui é que a produtividade é mais significativa e avaliada.

Há uma crença que todos os aspectos do trabalho docente, particularmente o ensino e a pesquisa, podem ser igualmente desenvolvidos nas tarefas de cada docente. Este princípio afirma que cada 
docente pode ser ou se espera que ele seja um docente completo, simultaneamente produtivo no ensino e na pesquisa. Nesta perspectiva os melhores acadêmicos são os melhores professores, e o melhor professor é um pesquisador que está a par do conteúdo e do método de uma área com envolvimento na pesquisa e que comunica o conhecimento com entusiasmo para os estudantes. Acredita-se ainda que o docente que faz pesquisa supostamente tem mais chance de introduzir o material de pesquisa nas aulas.

Estas crenças são codificadas na promoção e nos concursos da carreira docente onde o candidato é exigido demonstrar sua produtividade no ensino, na pesquisa e também na prestação de serviços à comunidade, mas este assunto sempre foi ignorado e nunca investigado em nosso meio.

\section{Relações entre o ensino e a pesquisa}

Não há evidência empírica clara que apoie o valor da pesquisa e da publicação para aumentar a efetividade do ensino. Mas há uma quantidade substancial de estudos que foram analisados e debatidos sobre o valor das publicaçóes dos professores na efetividade e sucesso do ensino.

WEBSTER $^{1}$ encontrou 10 estudos sobre a relação entre a pesquisa e o sucesso no ensino. Nenhum deles demonstrava correlaçáo positiva entre a produtividade na pesquisa e o sucesso no ensino. FeldMAN $^{2}$ revisou mais de 200 pesquisas e encontrou pouca relação entre a avaliação dos estudantes sobre o ensino e as várias formas de produtividade de pesquisa (coeficiente de correlação geral de 0,12 ).

FAIRWEATHER ${ }^{3}$ investigou qual a porcentagem do corpo docente era produtivo no ensino e na pesquisa e que porcentagem era produtivo em ambos, em 25.780 docentes de 818 faculdades e universidades americanas. Os resultados revelaram que a obtenção de altos níveis de produtividade no ensino e na pesquisa era relativamente rara (apenas 22\% dos docentes). Para a maioria dos docentes muitas horas de aula e de contato com os estudantes diminuía a taxa de publicaçáo e vice versa. A pequena porcentagem que obteve níveis elevados de produtividade em pesquisa e ensino da uma ideia de quanto falsa é a crença que cada docente pode ser produtivo no ensino e na pesquisa simultaneamente.

Hattie e MARSH ${ }^{4}$ realizaram uma meta análise em estudos que exploravam a relação entre o ensino e a pesquisa entre professores universitários. Baseados em 58 artigos e em 498 correlaçóes chegaram a uma correlação geral de 0,06. Eles usaram para avaliar a qualidade do ensino a avaliação feita pelos estudantes e a avaliação dos pares. Em relação à pesquisa usaram medidas de produtividade, qualidade das pesquisas e número de citaçóes. Quando verificaram a relação entre o tempo gasto na pesquisa e o tempo gasto no ensino encontraram uma relação negativa $(-0,56)$ entre eles, embora a produtividade na pesquisa fosse significantemente relacionada ao tempo gasto na pesquisa mas não com o tempo gasto no ensino. Neste mesmo estudo, quando eles verificaram a relação por áreas das universidades encontraram um coeficiente de correlação de 0,07 para as Humanas, 0,10 para as Ciências Sociais e 0,00 para as Ciências Naturais.

TANner et al. ${ }^{5}$ realizaram um estudo com professores de administração usando a opinião dos estudantes como efetividade do ensino e o número de publicaçóes como uma medida da produtividade em pesquisa e encontraram uma fraca relação entre ambas as atividades.

Na mesma linha de pesquisa, TAYLOR e STANTON ${ }^{6}$ investigaram 136 professores de administração para verificar suas atitudes para com a pesquisa e publicação e seu papel na contribuição da efetividade do ensino. Os resultados mostraram perspectivas conflitantes. A maioria dos professores acreditava que as atividades de pesquisa os tornavam melhores no ensino, mas as obrigaçóes com o ensino interferiam na realização de suas pesquisas. Muitos $(67,4 \%)$ também admitiram que só publicavam para assegurar a publicação e não para fazer avançar o corpo de conhecimento nas suas disciplinas. Enquanto 57,1\% concordavam que o ensino interferia nas atividades de pesquisa, apenas $33,1 \%$ concordavam que a pesquisa interferia na efetividade do ensino. $\mathrm{O}$ mais surpreendente foi a quantidade deles $(83,8 \%)$ que admitiam passar menos tempo fazendo pesquisa se não fosse para a promoção, a carreira acadêmica e a segurança no trabalho. Além de não se encontrar uma correlação positiva forte entre o ensino e a pesquisa muita acadêmicos eram de opiniấo que a maioria das pesquisas publicadas tinha valor duvidoso e que o resultado da ênfase em pesquisa tinha um impacto negativo na educação.

Allman $^{7}$ já alertava a um bom tempo que havia vários abusos na publicação das pesquisas. Estes 
abusos incluíam pesquisas falhas, a lista excessiva de autores nas pesquisas, estudos com resultados inflados e a publicação de "partes" da pesquisa para maximizar a quantidade de publicaçóes. A ênfase atual na quantidade de publicaçóes tem originado todos os abusos citados por Allman há mais de 20 anos. Naquela época ele já defendia a ideia que "se $80 \%$ dos artigos não fossem publicados, o progresso das ciências não seria afetado" porque muitos dos artigos continham resultados fúteis e desinteressantes.

A maioria dos milhares de artigos publicados a cada ano renegou o sistema de publicação a um esquema que serve apenas para "encher" o currículo ou o memorial e avançar na carreira acadêmica, além de inchar as bibliotecas com material iletrado, ilusório, sem valor e muito pouco relevante para os profissionais. É conhecimento estabelecido, não baseado em pesquisas empíricas, que o ensino e a pesquisa são atividades indissociáveis, não separáveis, que se apoiam reciprocamente. Uma das razóes para a existência das universidades de pesquisa é que essas duas atividades deveriam se apoiar mutuamente na mesma instituição. Muitos, porém, contestam com argumentos fortes que elas são conflitantes e não relacionadas entre si.

$\mathrm{Na}$ Universidade de São Paulo isto tem sido proclamado desde a sua criação e tem sido defendido, principalmente por administradores, até os dias atuais. Será que este conceito estabelecido 80 anos atrás ainda faz sentido? Não necessariamente. Hoje em dia, na Universidade existe um valor hierárquico no qual a pesquisa está no topo da pirâmide, seguida pelo ensino e depois pelos serviços de extensão. Esta hierarquia não reflete necessariamente os objetivos dos alunos, nem do público que sustenta a universidade pública através dos impostos. Eles acreditam que o ensino deve ser o trabalho principal, mesmo nas universidades de pesquisa. Embora as universidades de pesquisa sejam necessárias em qualquer país, seus custos e organização não permitem que todas elas sejam organizadas sob esta forma, principalmente as particulares. Mesmo dentro de uma única universidade pública não são todas as áreas que têm vocação para a pesquisa, mas pelas pressóes existentes todas agem como se tivessem. Nenhuma universidade pode fazer pesquisa de bom nível em todas as áreas. Os Estados Unidos da América têm mais de 1000 universidades, mas apenas 20 ou 30 delas fazem ciência de nível elevado. Nosso país conta com 65-70 mil docentes no ensino superior onde cerca de 40 mil são pagos para fazer pesquisa. Há dados segundo os quais cerca da metade não produziu absolutamente nenhuma pesquisa nos últimos três anos. A ideia da indissociabilidade do ensino e da pesquisa, isto é, que só a vivência contínua em ciência permite ensinar bem, é equivocada e nociva ao ensino superior. $\mathrm{O}$ que tem acontecido é que o ensino foi relegado a um segundo plano, negligenciado nas suas responsabilidades para se dedicar à pesquisa e publicaçóes. $\mathrm{O}$ tempo e energia gastos para fazer pesquisa são limitados pelo tempo exigido pelo ensino e vice-versa. É claro que ensino, aqui, deve ser interpretado de forma bem ampla que inclui aulas, orientaçóes, desenvolvimento e preparação dos conteúdos, atendimento aos alunos, supervisão dos trabalhos, etc.

Produtividade tanto no ensino como na pesquisa é um trabalho exigente, por isso é quase impossível ter excelência em ambos os domínios. $\mathrm{O}$ tempo e a energia necessários para um bom ensino ou para a realização da pesquisa são tantos que o destaque em um impede a excelência em outro, tanto é que o tempo gasto no ensino e o tempo gasto na pesquisa são correlacionados negativamente ${ }^{4}$.

Pesquisa e ensino são coisas correlatas, mas não idênticas e o peso de cada um pode torná-las concorrentes se não forem devidamente calibradas. Nos últimos anos a universidade tem se preocupado mais em formar bons pesquisadores do que bons profissionais, quando o país precisa de ambos. A atividade meio (pesquisa) tem prejudicado a atividade fim (ensino). Para que uma unidade venha a cumprir sua missão é preciso retraduzir alguns de seus princípios fundamentais e a indissociabilidade entre o ensino e a pesquisa, longe de ser um princípio básico, foi uma estratégia circunstancial de implantação da universidade.

Investigaçóes em nosso meio são necessárias para melhor entender como a produção em pesquisa está relacionada aos outros objetivos do ensino superior, mas, por enquanto, isto não está na moda. 


\begin{abstract}
Teaching and researching: conflicting activities

University professor have three major responsibilities to the students and comunity: teaching, researching and extension services. The purpose of this essay was to analyse the relationship between teaching effectiveness and researching productivity. Several studies showed no relationship between teaching and researching. According to this review it is concluded that the common belief that teaching and research are inextrincably entwined is na enduring myth, injustifiable today.
\end{abstract}

KEY WORDS: University professor; Teaching; Researching; Service.

\title{
Referências
}

1. Webster DS. Does research productivity enhance teaching? Educ Record. 1966;66:60-3.

2. Feldman K. Research productivity and scholarly accomplishment of college teachers as related to their instructional effectiveness: a review and exploration. Res High Educ. 1987;26:227-98.

3. Fairweather JS. The mythologies of faculty productivity. J High Educ. 2002;73:26-48.

4. Hattie J, Marsh HW. The relationship between research and teaching: a meta analysis. Rev Educ Res. 1996;66:507-42.

5. Tanner J, Totaro M, Hotard D. Research productivity and teaching effectiveness: MISfaculty. J Comp Inform Syst. 1999;39:8-15.

6. Taylor RL, Stanton AD. Academic publishing and teaching effectiveness: an attitudinal study of AACSB accreditation business school faculty. Acad Educ Leadership J. 2009;13:93-106.

7. Allman WF. Drowning in a sea of knowledge. U S News World Rep. 1995;105:59.

\begin{tabular}{r|r} 
ENDEREÇo & \\
Valdir Barbanti & \\
Departamento de Esporte & Recebido para publicação: 19/09/2014 \\
Escola de Educação Física e Esporte- USP & Aceito: 06/10/2014 \\
Av. Prof. Mello Moraes, 65 & \\
$05508-030$ - São Paulo - SP - BRASIL & \\
e-mail: barbanti@usp.br &
\end{tabular}

162 • Rev Bras Educ Fís Esporte, (São Paulo) 2015J an-Mar; 29(1):159-62 